American Journal of Applied Sciences 9 (6): 865-873, 2012

ISSN 1546-9239

(C) 2012 Science Publications

\title{
Evaluating Public Participation Process in Development Projects in Thailand: A Case Study of the Hin Krut Power Plant Project
}

\author{
${ }^{1}$ Chutarat Chompunth and ${ }^{2}$ Suphattharachai Chomphan \\ ${ }^{1}$ School of Social and Environmental Development, \\ National Institute of Development Administration, \\ 118 M.3, Serithai Road, Klong-Chan, Bangkapi, Bangkok, 10240, Thailand \\ ${ }^{2}$ Department of Electrical Engineering, Faculty of Engineering at Si Racha, \\ Kasetsart University, 199 M.6, Tungsukhla, Si Racha, Chonburi, 20230, Thailand
}

\begin{abstract}
Problem statement: Public participation has become a vital element of environmental decision-making. Although public participation has grown tremendously in Thailand due to a rising pressure from the public, this practice often fails to solve environmental problems and conflicts. There is a keen for a systematic evaluation of the public participation process to investigate whether the participation process is effective and what works or does not work in this respect. Approach: This study evaluates the effectiveness of the public participation process of the Hin Krut power plant project through an evaluation model developed from relevant literatures. Results: It was found that the public participation process of the case study was not completely effective when tested against the evaluation criteria. The affected people had no chance to present any comments at the very beginning. The public participation process started too late, after a decision had been made and conflicts among stakeholders already occurred. Conclusion: The public participation process is not yet properly established in the Thai context. There is an urgent need to find a working model and conditions of public participation which can assist in resolving environmental problems. Finally, a set of recommendations for improving public participation process are suggested.
\end{abstract}

Key words: Public participation, environmental decision-making process, conflict, power plant

\section{INTRODUCTION}

Thailand's rapid economic growth and industrialization over the last four decades have led to significant environmental challenges. The Thai government recognizes the linkage between continued economic prosperity and the protection of the environment. Thus, the concept of public participation in the environmental decision-making process through a number of laws and legal requirements was established and the public began to recognize their rights granted by laws. Although a foundation for involvement in the decision-making process is provided to the public, this is still in the early stage of implementation.

Public participation is a continuing challenge in Thailand. A number of development projects initiated either by the government or the private sectors frequently face strong public opposition and the public participation process itself is viewed as unsuccessful practice. The question of how to be sure that the participation process is effective and results in desirable outcomes seems to be vital (Rowe and Frewer, 2004). A systematic evaluation of public participation is essential as a means to ensure the acceptance of the process and outcomes and, importantly, to develop knowledge of how to improve the practice (Charnley and Engelbert, 2005).

This study is important to Thailand because it highlights the significance of conducting public participation in the implementation of development projects in Thailand and identifies the critical factors for effective practice of public participation. The public participation processes of the Hin Krut power plant was evaluated to provide evidence to answer the research questions of this study that is: How effective is public participation for managing environmental conflict management in development projects in the Thai contexts?

Corresponding Author: Chutarat Chompunth, School of Social and Environmental Development,

National Institute of Development Administration, 118 M.3, Serithai Road,

Klong-Chan, Bangkapi, Bangkok, 10240, Thailand 
The research findings and recommendations are vital to improve the public participation practice in Thailand and to enable all stakeholders to effectively participate in the decision-making process.

\section{MATERIALS AND METHODS}

A conceptual framework of public participation: What is public participation? The term public participation has numerous different meanings and definitions. Different authors have different meanings when using the term 'public participation' depending on who the people are and what the setting is. It is always viewed differently depending on its contexts and purposes. In the past, public participation was considered as being an opportunity to give comments in a public hearing, to vote in referendums, or just being a member of a social movement society. Frequently, public participation related to participation at public hearings only, but, at present, this term refers to a diversity of procedures for facilitating members of the public to be effective participants in deliberations in decision-making processes (Webler and Tuler, 2006).

The concept of public participation needs to be clearly identified, in particular in the context of environmental use. Therefore, a variety of meanings of public participation from different researchers in different fields was determined in order to develop the ideas and integrate concepts to define the most appropriate meaning of public participation in the specific context of this research. In this study, public participation is defined as: "a range of activities, or processes, by which all affected and interested parties are engaged in the decision-making process to prevent or resolve a conflict and to achieve consensus and its objective through a mutual two-way communication before decisions are made".

Effective public participation: When a government or a private agency employs public participation in their activities, there is a substantial interest in determining whether or not their endeavors have been successful. To begin with, it is important to clearly verify and define what successful or effective public participation means. In general, the effectiveness can define as: "whether something works as intended an meets the purpose (s) for which it is designed". However, indeed, the definition of effectiveness is typically complicated because of a diversity of objectives and expectations for public participation processes and mechanisms. The definition and interpretation can vary depending on participants' and stakeholders' perspectives, contexts and situations. Specific political, social and economic contexts in each country typically have an influence on the effectiveness of public participation. For these reasons, developing a single universal definition of effective public participation is difficult.

In terms of process effectiveness, many scholars indicate that process effectiveness focuses primarily on means rather than ends. It is therefore, to examine a variety of procedural aspects of the participatory programs that add value to a decision making process. These factors include; procedural justice, accessibility to the decision making process, inclusiveness, diversity of views represented, opportunities for participation, information exchange, identification and integration of concerns, early involvement of stakeholders, number of options identified, number/types of participants, decision maker presence at meetings, availability and clarity of materials.

For some practitioners, the success of a public participation endeavor can be judged in terms of results or outcomes. They proposed important outcomes in term of; project/decision acceptability, mutual learning, improved understanding and conflict resolution (Shepherd and Ortolano, 1997). However, in practice, it is difficult to facilitate public participation processes to achieve all desired elements.

Effective participation should be perceived as a means to enhance effective decision making through an opening-up of the decision process to public views. Through this approach, public participation could constitute accountability and transparency to the decision-making process. These elements should be used as an outline when the practitioner designs a public participation program (Bond et al., 2004). Thus, for public participation to be effective in any context, it requires the public to be well informed and kept aware of the possibility of participation.

Conclusively, the definitions of effectiveness are pretty much influence by individual expectations and interpretations. Thus, it can be summarized that that there is no single definition of effective participation processes (Cashmore et al., 2004). However, in this study, effective public participation is defined as: "A process that has clear objective(s); initiates early enough to allow participants to influence the decision; is inclusive; increases transparency; empowers people; fosters two-way communication and learning process; seeks for a consensus and resolves conflicts among stakeholders".

A development of evaluation frameworks for public participation: Obviously, the existing evaluation approaches vary widely with regards to differences in concept, purpose, focus, scope, methodology and disciplinary perspective. Besides, different stakeholders may have different objectives and measurements. 
Am. J. Applied Sci., 9 (6): 865-873, 2012

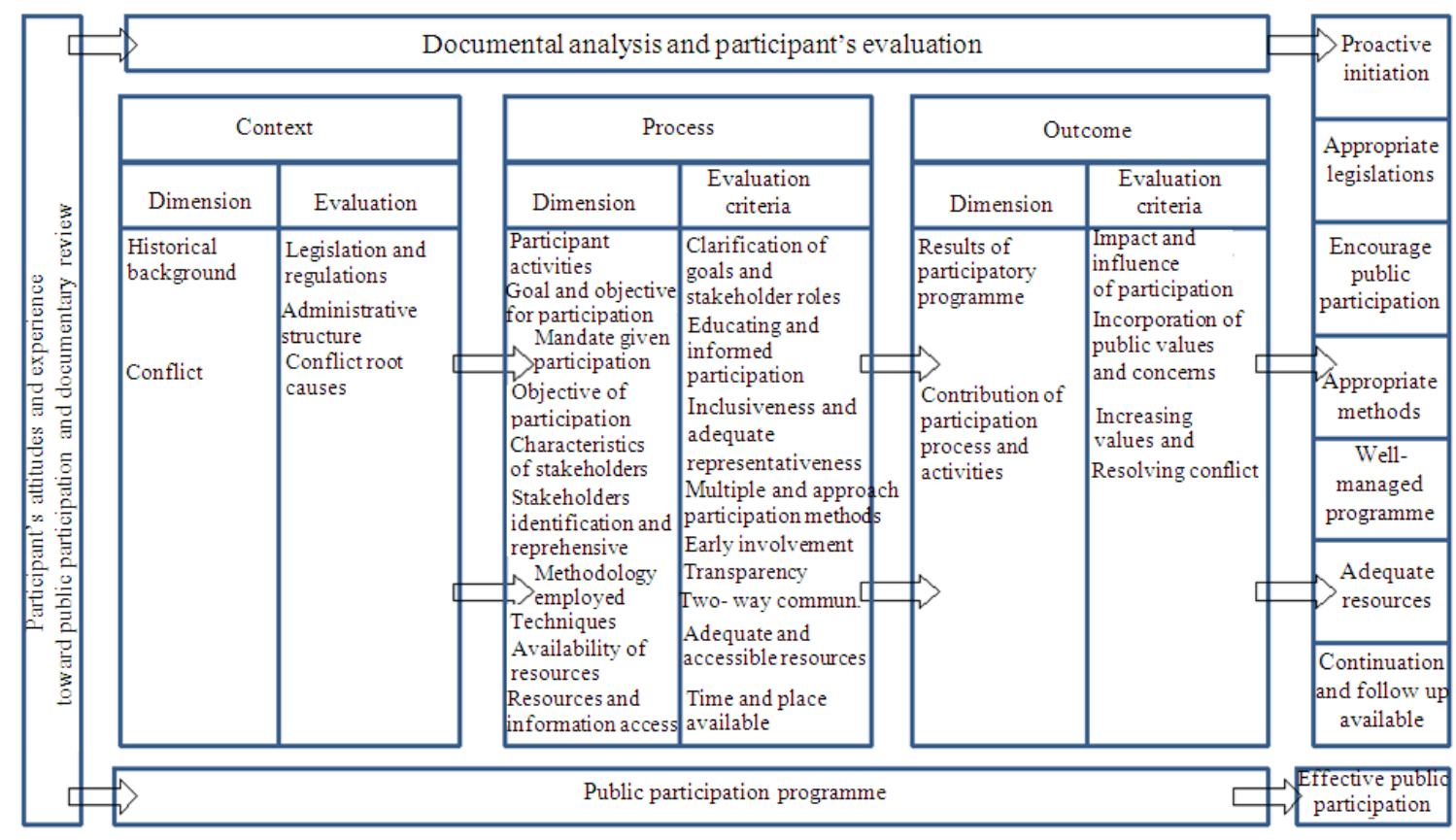

Fig. 1: An evaluation model of public participation program

As a result, the evaluations in the participation field have been applied from a variety of theories such as public participation theory, communication theory and democratic theory (Fiorino, 1990). Indeed, the approaches to public participation evaluations are primarily developed from the traditional evaluation that focused on whether public participation achieves either process or outcome goals (Chess and Purcell, 1999).

Most acknowledged evaluation approaches of public participation are related to the effectiveness of the construction and implementation of the participation procedure and the success of the outcome. The participatory process-based evaluation typically measures fairness and competence matters, interchanged information, inclusiveness and procedures. This includes the evaluation for how effective public participation is in democratic decision-making (Chess, 2000). The outcome-based evaluation uses indicators of how stakeholders influence decisions, their satisfaction with the final decisions, or an ability to reach a consensus. This approach is not only based on stakeholders' or users' goals, but it also includes social goals.

In order to make a rigorous evaluation of public participation processes and build generalizable conclusions, some consistency in theoretical frameworks is essential and needed. An evaluation model for the evaluation of the public participation process of this study is developed and presented in Fig. 1. Moving from left to right of the picture, the framework depicts the three main phases of evaluation; the context in which the participation takes place; the process of the participation conducted; and, the outcome of that participation program. The model focuses on the different perspectives of the participants' in the public participation process as well as the roles and influences that they had. The measurements of these phases are analyzed to represent the effectiveness of the public participation. Effectiveness is portrayed in term of relevant indices based on stakeholders' responses which revealed their perceptions, attitudes and satisfactions. However, in this study presents and discusses only the research findings of the second and third phases of the model.

In the middle of the figure, a large body of evaluation focuses exclusively on the study of the effectiveness of the public participation process. This framework defines a need to evaluate the participation of various participants against their own perspectives that may influence their involvement with the process.

First, an evaluation of participant activities aims at assessing how well the goals and stakeholder roles were clarified to the public and how well the public were educated and informed by the authorities. Second, evaluating the characteristics of stakeholders focuses on an identification of stakeholders and the inclusiveness and adequate representativeness of the participants. The evaluation focuses on how well these aspects were 
implemented. Third, an evaluation of methodology employed stresses how the participation methods were employed including how appropriate the techniques were, when they were employed, how transparent they were and how they were employed. The interactions among stakeholders are also the focus of the analysis. Finally, an evaluation of an availability of resources emphasizes how adequate and accessible the participation resources were, in particular the information and how they were provided. The evaluation also investigates the time and place of the participation process.

To the right of the figure is the evaluation of the outcomes of the participation process, which are measured concerning the stakeholders' level of viewpoints and experience. This evaluation depicts an outcome evaluation; the results of the participation program. An evaluation focuses on an evaluation of impacts and influence of the participation process and an integration of public values and concerns to the decision-making process.

It can be seen that this evaluation framework attempts to make more explicit the factors that should be considered when evaluating both the processes and outcomes of a public participation process. The framework facilitates a balanced evaluation that indicates not only effectiveness but also the factors instrumental to that effectiveness. The evaluation criteria also encompass substantial consideration of the participation processes and outcomes. Unquestionably, a systematic evaluation provides meaningful and useful information that can be used to improve public participation processes (Charnley and Engelbert, 2005).

Methodology: A single case study was adopted as an inquiry strategy for this thesis in order to conduct an indepth study of the public participation practices in the Thai context. To achieve broader and better data and results, mixed methods of data collection were carried out. The first method was a review of documents concerning the operations, activities and concepts of public participation process. A need for in-depth information of public participation processes and their outcomes also led to the decision to carry out interviews with a wide range of stakeholders of the study project. Thus, interviews were selected, including structured, semi-structured and in-depth interviews with stakeholders. Stakeholders who held key positions or played important roles in the public participation process were identified for interviews.

\section{RESULTS}

Process-based evaluation; Clarification of goals and stakeholder roles: In this study, it was found that the villagers were not informed clearly about the purpose of the participation process and their roles, including how the outcome of the process would be used. The government was not aware enough of these issues. This brought a variance in expectations and a misunderstanding which negatively affected the participation process. From the research findings, it could be suggested that to avoid the problems of misunderstanding and conflicting expectations and partial and irrelevant outcomes from the public participation process, it is important to make sure that the purpose, intentions and scope of the process are clearly identified and agreed before the process starts.

Similarly, in other research it was found that before the beginning of the public participation process, all participants should have a clear understanding of what the participation purpose is and what the process and outcome of the participation process would be, from the authorities (Tippett et al., 2005). This is because a clear plan of public participation containing clear aims, the participants' roles and responsibilities, combined with effective communication in a proper time line, is an important factor to minimize confusion and unrealistic expectations from all stakeholders which could exacerbate distrust and cause dissatisfaction and frustration.

Educating and informing the public: In the Hin Krut case, most of the affected villagers did not receive any support to increase their knowledge about the issues from the authorities and the project proponents. They learned about the problems and project information through their meetings and seminars which were mostly set up through their own efforts. However, these activities were initiated by different parties and the villagers preferred to attend only activities conducted by those whose views reflected their own. Particularly, the opponents refused to participate in many events organised by the developers. Although they had developed a high level of understanding in the issue and alternatives, this was not enough to make them feel effective in the process. It was found that the public needed to increase their knowledge in the problems, projects and alternatives, as well as the different viewpoints of other parties, in order to meaningfully participate in the process.

Similarly, it has been found that when insufficient effort was devoted to educating the public, the participants would be powerless to engage in the decision-making process. To make public participation more effective, a collaborative and constructive learning process was required: participants should not only simply exchange information, but they also take part in the 
process of learning the problems and developing alternatives by means of a meaningful social learning process in which stakeholders' concerns were a priority.

Inclusiveness and adequate representativeness: In this study, inclusiveness of the participants was not achieved due to some constraints such as strong opposing ideas of the protestors or unclear practical guidelines. The authorities and the developers did not try enough to engage stakeholders, particularly the affected villagers, at the beginning of the project implementation. After the conflict occurred, a participation process was then initiated. Most protestors refused to take part in these programs run by either the authorities or the developers and made it difficult for the government to engage all parties in the participation process. Besides, there were problems in practice when selecting the right participants due to selection criteria not being clear. For example, the participants in the public hearing case were identified and selected by a top-down approach which seemed to engage all stakeholders; however, the authorities did not make clear who the stakeholders were and who should participate in the process. Thus, it was hard to say that the opinions and comments from the participation process represented the voice of all people affected by the project. The finding suggested that the authorities should give the first priority to participate in the process to lay people in the impacted area who were directly impacted from the development project.

A similar finding was evident in other research (Dungumaro and Madulu, 2003; Vantanen and Marttunen, 2005). It was found that it was difficult to engage an appropriate and inclusive representative cross section of the entire community in a participation process. Local villagers and stakeholders who would be directly affected by, or benefit from the decision and were closer to the project, should have first opportunity to participate and present their concerns. Stakeholders who felt they were excluded from the decision-making process would mount strong opposition to the project or policy initiatives which could delay or cancel the implementation.

Multiple and appropriate participation methods: A number of participation techniques were used to engage and communicate with the public; nonetheless, they were not conducted at the early stage of the project, particularly after the conflict occurred. These techniques ranged from traditional methods on an education and information provision level, to a more interactive approach such as public meetings. However, the majority of them were traditional. The public did not have more opportunities to discuss the issue and manipulate the decision.
The selected participation methods, particularly a public hearing, seemed not to be appropriate to the situation and the involved parties. Indeed, the government usually used public hearings to solicit the public's opinions and solve conflict among stakeholders in development projects; however, more often the public hearing was not successful in solving the conflict in Thai society, as clearly presented in this project. Many affected villagers were frustrated with the participation process and their government because they felt that the process was not a participation process in which they could make any change to the decision or create appropriate dialogue.

Similarly, it has been found that, although traditional methods were being widely used, they focused on one-way transmission of information from the developer or the authority to the public and the public had less opportunity to input into an early stage of the decision-making processes (Fiorino, 1990).

Early involvement: When the Hin Krut power plant was first initiated, it was implemented without providing opportunities for the public to take part early enough in project development. The affected people had no chance to present any comments at the very beginning. The public participation process started too late, after a decision has been made and conflicts among stakeholders already occurred. Clearly, the public had little power to influence the decision and nothing could be changed. It could be said that, in this study, a lack of public participation in the early stage of project implementation became the critical problem.

This issue is a critical problem in practice in many countries, such as the Czech Republic (Richardson et al., 1998), Spain (Palerm, 1999), Bulgaria (Almer and Koontz, 2004) and Kenya (Okello et al., 2009). The public participation taken place late, particularly when decisions have already been taken, could be ineffective and obstructed by the public. This was because it was too late for the public to make meaningful contributions and its voice might have less power to influence the decisions.

Transparency: In this study, the participation process seemed not to be open and transparent enough. All decisions were decided before an involvement of the public; thus the public could not see how the decisions were being made. For example, the contract was already signed and the construction had been approved before the public had any details about the project. The affected villagers did not have an opportunity to participate through the processes. After the public hearing, the committee could not clearly explain how 
Am. J. Applied Sci., 9 (6): 865-873, 2012

the public input was incorporated into the decisionmaking process. The hearing report and conclusion was not widely publicized in order to communicate the results back to the participants. The finding showed that if the participation process was credible, transparent and legitimate, the project would be more accepted and increase public satisfaction with decisions or even be successfully implemented.

There is considerable empirical evidence of a lack of transparency in many studies (Dungumaro and Madulu, 2003; Diduck et al., 2007). This research showed that the decision-making and public participation processes failed to be transparent. An integration of public inputs into the decision-making process was poor and hardly existed. In particular, the information circulated back to participants had little evidence of how the participation process had an impact on the final decision.

Two-way communication: The communication approach in this case was mainly a one-way approach. A DAD strategy of the government was a good example of a one-way communication of messages from the government to the public. The developer had more important roles than other stakeholders, while the public, particularly the affected villagers, had less power in negotiating with other parties. The communication was mainly a one-way approach from the developers which was based on information provision and insufficient dialogue. This might be because both the government and developer wanted the villagers to be a passive participant, relying on only the information they provided and accepting what they planned for them. A limitation of public access to official communication channels and forums was predominant. Obviously, two-ways communication among stakeholders was not well established in this project and this caused misunderstanding among stakeholders. In this study, the participants wanted to see participation processes conveyed in a two-way flow of information as well as encouraging open discussion and debate.

Comparable findings are evident in other studies (Palerm, 1999). They found that a lack of two-way communication increased the possibility of conflicts whilst decreasing the potential for reaching a consensus. In agreement, it was suggested that the participation process should be employed by involving more extensive two-way communication.

Resource and information availability and accessibility in this study, provision of resources was insufficient and unsatisfactory. Most relevant information was difficult to access and not available to the public. The public had difficultly accessing all data and information related to the project, maintained either by the government or the project proponent. Besides, this information was inappropriate and incomprehensible for many participants since most of if was in English and had many technical terms, such as the EIA report. There were also some mistakes in the EIA report. This led to mistrust in other information provided by the government and the developers. Additionally, the participation programs, particularly public hearings, were conducted on workdays which means a number of people were unable to attend.

From the research findings, it was found that receiving, sharing and exchanging precise, correct and updated information about the project was critical for project implementation. The public required sufficient information which was relevant and accessible to increase their knowledge and understanding and enable them to meaningfully participate in the process.

A number of scholars stated that people could not effectively evaluate the problems and alternatives unless they were provided with appropriate and sufficient information. These resources are important and must be provided to the public in order to achieve an effective participation process (Bond et al., 2004; Tippett et al., 2005).

Outcome-based evaluation; Impact and influence of participation: In this study, it was clearly presented that in the traditional management style of the Thai government, the public was often excluded from the decision-making process and the public did not have any power over the decision. The public input hardly influenced the decision-making process of the government. The public were provided little opportunity to comment on, or contribute to, any aspect of the project in any participation programs. It might be said that the decision-makers did not want to distribute their power to the local people, or even the local government bodies. Importantly, they did not intend to promote public participation at any level.

When the impacted villagers found that their involvement was too late and could not impact on the decision or even make any change to the project, so they preferred not to participate in the government's or the project owner's participation processes and began their protest activities. Clearly, the public needed to have a genuine opportunity to be heard and influence the final decisions.

This problem also has been found in many countries, such as Bulgaria (Almer and Koontz, 2004), India (Diduck et al., 2007) and the UK. It was found that the outcomes of the public participation process have failed to be reflected in the decision-making stage 
and the final decisions. While the public expected that they should have a real influence in decision-making, they had a marginal influence only on what really happened. Indeed, empowering was not only power sharing and free access to information, but also an efficient transfer of necessary competency to the public.

Incorporation of public values and concerns: Clearly, in this study, the local villagers tried to add their knowledge and concerns into the process. However, there was no obvious evidence that the public input or the outcomes of the participation process were brought and soundly integrated into the decisionmaking process. The public input hardly influenced the decision-making process of the government. Although the project was cancelled, there was no official evidence presented that the public input influenced the final decision. The decision-making process remained with the government.

Indeed, the public hold specific and valuable information, particularly local geography, the local ways of life, environmental conditions or other relevant factors that can influence the operation and safety of the project. This knowledge was potentially valuable to the decision-making process and should not be overlooked. Integrating this local knowledge and values into the decision-making processes could assist in finding consensus which leads to more accountability and legitimacy that satisfies a broader public. Undoubtedly, this study found that the public needed to ensure that their viewpoints and concerns were meaningfully incorporated into the decision-making process.

The public participation process needed to be conducted carefully to ensure that all stakeholders were given opportunities to voice their ideas and concerns and every interest was considered fairly. This would eventually lead to a better decision and conflict resolution (Richardson et al., 1998).

Values and trust: Evidently, this study showed that trust among stakeholders, in particular among the affected villagers, the government and the developer was problematic. Particularly, trust and confidence in the government decreased since non-transparent administration by the government was prevalent. The public could not see the government's willingness to support them and be transparent in its decisions. The decision-making process was conducted without consulting the public. Besides, the government and the developers failed to make the public believe in minimized social and environmental impacts including monitoring programs of the power plant. Thus, low levels of trust were prevalent.
This finding tallies with results from a number of studies (Shepherd and Ortolano, 1997; Tippett et al., 2005), which presented that a lack of trust led to protest and antagonism among stakeholders. When the stakeholders did not trust each other, cooperation hardly existed.

Resolving conflict: Conflicts of the Hin Krut case were serious which mainly resulted from a lack of public participation. Evidently, the public was excluded from the decision from the beginning, so they thought the project was not transparent and did not accept it. The public tried to make their voices heard but they were overlooked. Later, although there had been an attempt to resolve conflicts between the protestors and the developer, it proved to be too late. For example, the public hearing's function was often to communicate prior decisions to the attendees rather than to foster discussion and problem solving to reach consensus. The developers and the officers claimed that they tried their best to resolve the conflict while the villagers viewed that they were not willing to do so. These conflicts were too complicated and difficult to handle.

Clearly, the participation process did not reach consensus on a written agreement. The conflict could not be resolved and was even made worse. However, although the conflicts were not resolved, the stakeholders learned to understand the participation practice, express their views and exchange ideas with other parties. This could lead to an improvement of the public participation process.

Similar finding was found in other studies that different stakeholders and parties looked for different approaches to achieve their own concerns and interests (Bond et al., 2004). This point is hard to handle it since it was very difficult to make everyone agree with a decision. Importantly, conflicts could not be solved if the process of decision making is perceived to be unfair or biased.

\section{DISCUSSION}

The study found that in Thailand the public participation process of the Hin Krut power plant project was not completely effective when tested against the evaluation criteria. The inclusiveness of stakeholders in participation process was not achieved due to some constraints such as strong opposing ideas of the protestors or unclear practical guidelines. The affected people had no chance to present any comments at the very beginning. The public participation process started too late, after a decision has been made and conflicts among stakeholders already occurred. The 
public had little power to influence the decision and nothing could be changed. In this case study, a number of participation techniques were used to engage and communicate with the public; nonetheless, they were not conducted at the early stage of the project. These techniques ranged from traditional methods on an education and information provision level, to a more interactive approach such as public meetings. In the decision-making process, the participation process seemed not to be open and transparent enough. All decisions were decided before an involvement of the public; thus the public could not see how the decisions were being made. Importantly, the conflict among stakeholders was not resolved and hostility towards the project was not eliminated.

According to the specific and dynamic context of governance in Thai society, public participation techniques should be carefully considered to be properly applied in this specific context. There is no consensus on a format for public participation. The public participation process should not concentrate only on increasing the higher levels of participation but a full set of conditions for effective participation should be established. It could be said that there is no single component that contributes to effective public participation, rather a combination of components, because public participation is multi-dimensional and complex (Bond et al., 2004). Most of the components are interdependent and there must be a combination of components to make any program meaningful. Consequently, when one factor deteriorates it is difficult for the other elements to be incorporated to their full capability. Indeed, "public participation is far too complicated to come to easy conclusions about what works and why". For example, a failure to achieve inclusiveness of stakeholders in the participation process can lead to a lack of trust and cooperation in an implementation of the development project from stakeholders who were excluded from the process and a project will be seen as lacking transparency (Tippett $e t$ al., 2005). The legitimacy of the decision-making process is potentially affected either by the extent to which inclusiveness of the stakeholders is achieved or when the participation process is conducted.

It could be implied that effective public participation is not a single event, but a carefully designed and planned process that applies a multiplicity of techniques suited to the situations, contexts and the communities involved. To achieve it, it is very important to plan and execute the process very carefully, allowing adequate time and resources (Shepherd and Ortolano, 1997). The participation issues need to be clearly framed and communicated before the processes are commenced. The sessions should be employed in two-way communication and sufficient information should be exchanged.

From this study, it is recommended that public participation should be considered as obligatory in any development project and local communities should be empowered as equal development partners who should participate in activities related to development projects, in particular, in the design, implementation, mitigation and benefit sharing aspects. This confirms that public participation was more than a procedural obligation to comply with in development project implementation (Dungumaro and Madulu, 2003). It can provide extensive advantages to the whole of society in particular preventing, minimizing and resolving conflicts, developing trust and co-operation among stakeholders, increasing acceptance in projects, establishing democratic involvement and improving the environmental decision-making process and its outcome (Shepherd and Ortolano, 1997).

\section{CONCLUSION}

Public participation processes seem to be a rational strategy for a developing country with a poor economy and struggling democracy like Thailand. However, in this study, it was found that public participation of Thai people did not comply with a real concept of public participation; people who were stakeholders in the project did not have an opportunity to be informed and to express their ideas from the very beginning and their opinions were not considered in the decision-making process. It could be said that the public participation process was not yet properly established in the Thai context. Thus, there is an urgent need to find a working model and conditions of public participation which can assist in resolving environmental problems.

Effective public participation in environmental issues requires motivation and effort from all stakeholders. Particularly, it requires skills from the authorities and trust and confidence from the public. However, this might need more time to cultivate and develop. If public participation is credible, transparent and legitimate, the process could simply reach an acceptable and desirable outcome for every party. A legitimate public participation process is a potential approach to effectively resolve conflict over large-scale development projects in every context in non violent ways.

Finally, various assumptions discussed previously in this study could lead to a conclusion that public participation is the pre-eminent approach to achieve a 
balance desired between stakeholders from development projects or policy implementation. By providing public participation from the beginning through until the end of the process, it could: reduce strong opposition since the public could be involved before the decision has been made; resolve conflict and lessen anger from the public; and, enhance the trust and credibility of the authority or developer.

\section{REFERENCES}

Almer, H.L. and T.M. Koontz, 2004. Public hearings for EIAs in post-communist Bulgaria: Do they work? Environ. Impact Assessment Rev., 24: 473493. DOI: 10.1016/j.eiar.2003.12.004

Bond, A., J. Palerm and P. Haigh, 2004. Public participation in EIA of nuclear power plant decommissioning projects: A case study analysis. Environ. Impact Assessment, 24: 617-641. DOI: 10.1016/j.eiar.2004.02.002

Cashmore, M., R. Gwilliam, R. Morgan, D. Cobb and A. Bond, 2004. The interminable issue of effectiveness: Substantive purposes, outcomes and research challenges in the advancement of environmental impact assessment theory. Impact Assessment Project Appraisal, 22: 295-310. DOI: 10.3152/147154604781765860

Charnley, S. and B. Engelbert, 2005. Evaluating public participation in environmental decision-making: EPA's superfund community involvement program. J. Environ. Manage., 77: 165-182. DOI: 10.1016/j.jenvman.2005.04.002

Chess, C. and K. Purcell, 1999. Public participation and the environment: Do we know what works? Environ. Sci. Technol., 33: 2685-2692. DOI: 10.1021/es980500g

Chess, C., 2000. Evaluating environmental public participation: Methodological questions. Environ. Plann. Manage., 43: 769-784. DOI: 10.1080/09640560020001674

Diduck, A., J. Sinclair, D. Pratap and G. Hostetler, 2007. Achieving meaningful public participation in the environmental assessment of hydro development: Case studies from Chamoli district, Uttarakhand, India. Impact Assessment Project Appraisal, 25: 219-231. DOI: 10.3152/146155107X217299

Dungumaro, E.W. and N.F. Madulu, 2003. Public participation in integrated water resources management: The case of Tanzania. Phys. Chem. Earth, 28: 1009-1014. DOI: 10.1016/j.pce.2003.08.042
Fiorino, D.J., 1990. Citizen participation and environmental risk: A survey of institutional mechanisms science. Technol. Hum. Values, 15: 226-243. DOI: 10.1177/016224399001500204

Okello, N., L. Beevers, W. Douven and J. Leentvaar, 2009. The doing and un-doing of public participation during environmental impact assessments in Kenya. Impact Assessment Project Appraisal, 27: 217-226. DOI: 10.3152/146155109X465940

Palerm, J.R., 1999. Public participation in environmental impact assessment in Spain: Three case studies evaluating national, Catalan and Balearic Legislation. Impact Assessment Project Appraisal, 17: 259-271. DOI: 10.3152/147154699781767675

Richardson, T., J. Dusik and P. Jindrova, 1998. Parallel public participation: An answer to inertia in decision-making. Environ. Impact Assessment Rev., 18: 201-216. DOI: 10.1016/S01959255(98)00007-9

Rowe, G. and L.J. Frewer, 2004. Evaluating public participation exercises: A research agenda. Sci. Technol. Hum. Values, 29: 512-557. DOI: 10.1177/0162243903259197

Shepherd, A. and L. Ortolano, 1997. Organizational change and environmental impact assessment at the electricity generating authority of Thailand: 19721988. Environ. Impact Assessment Rev., 17: 329356. DOI: 10.1016/S0195-9255(97)00025-5

Tippett, J., B. Searle, C. Pahl-Wostl and Y. Rees, 2005. Social learning in public participation in River Basin management: Early findings from harmoni COP European case studies. Environ. Sci. Policy, 8: 287-299. DOI: 10.1016/j.envsci.2005.03.003

Vantanen, A. and M. Marttunen, 2005. Public involvement in multi-objective water level regulation development Projects-evaluating the applicability of public involvement methods. Environ. Impact Assessment Rev., 25: 281-304. DOI: 10.1016/j.eiar.2004.09.004

Webler, T. and S. Tuler, 2006. Four perspectives on public participation process in environmental assessment and decision making: Combined results from 10 case studies. Policy Stud. J., 34: 699-722. DOI: 10.1111/j.1541-0072.2006.00198.x 